\title{
LCO flutter analysis on coir pressed mat fibre/epoxy composites plate
}

\begin{abstract}
The effects of aspect ratio and fiber-epoxy weight ratio of coir fibre/epoxy composite wing idealized as flat plate on flutter speed were preliminary studied in this current research to investigate the aeroelastic response on natural fiber composite material. The usage of natural material such as coir fiber reinforced composite might become possible solutions in future since it offers lower weight, cost reduction, and preservation of the environment factor compared to presence structures like conventional glass or carbon fiber as the reinforcement for composites. For this work, the analysis of coir fiber on aeroelastic problem will be preliminary investigated to establish related data to be served, especially in the aerospace research areas. The research began with the existing raw untreated coir fiber, which was in the form of pressed mat and originally in random oriented fiber forms, were set in the composite preparation process by simple hand-lay-up and compression moulding method under the room temperature and also controlled pressure conditions. Specimen with different aspect ratios (5, 6 and 7) with $25 \%$ wt fiber reinforcement composite was installed in the wind tunnel for subsonic experimental aeroelastic test. The result shows that the plates with lower aspect ratio have higher flutter speed.
\end{abstract}

Keyword: Coconut coir fibre; Flutter; Natural composite; Subsonic speed wind tunnel 